\title{
Prostaglandin synthesis in the male and female reproductive tract
}

\author{
R. W. Kelly \\ M.R.C. Unit of Reproductive Biology, 37 Chalmers St, Edinburgh EH3 9EW, U.K.
}

\section{Introduction}

Prostaglandins (PGs) and closely related compounds (prostanoids) are a family of lipid substances derived from arachidonic acid which have potent and diverse pharmacological actions. The result of much prostaglandin research over the past 50 years has been the demonstration of an ever increasing number of prostanoid structures. Some of these have actions which suggest a physiological role but there are also many prostanoid compounds without a clearly identified action and many are without obvious biological significance. In particular there has been little success to date in attributing a role to the major prostaglandins (PGs A to F). This is particularly apparent in reproductive physiology in which early work established high concentrations of PGE and PGF in human semen (von Euler, 1936) and in menstrual fluid (Pickles, 1957). The concentrations in semen and menstrual fluid probably represent the highest concentrations of PGs found in the human body and yet today we can do little but theorize on the role of PGs in the male and female reproductive tract.

The problem lies in the complexity of PG mixtures found in the male and female reproductive tracts and may be because prostaglandin biosynthesis forms part of the arachidonic acid cascade (Text-fig. 1) which contains many strained and labile structures and there is consequent extensive non-enzymic breakdown of many of the PGs and intermediates. The reports of large quantities of PGs of the A, B, 19-hydroxy A and 19-hydroxy B series in semen (Hamberg \& Samuelsson, 1966) are, therefore, probably due to non-enzymic activity during storage. Because of the existence of these non-enzymic pathways, it would be prudent to consider which of them could participate in arachidonic acid catabolism to give the prostaglandins we observe. The PGE and PGF observed in human semen and human endometrium can be formed non-enzymically from the endoperoxides PGG and PGH (Hamberg \& Samuelsson, 1974), and there may therefore be a pivotal role for the endoperoxides in both the male and female reproductive tract. This communication examines this possibility with particular emphasis on the secretions and content of the male accessory glands and the uterus.

\section{Male reproductive tract}

Human semen has 4 major components (Text-fig. 2), PGE-1 and PGE-2 (Samuelsson, 1963) and 19-hydroxy PGE-1 and 19-hydroxy PGE-2 (Taylor \& Kelly, 1974; Jonsson, Middleditch \& Desiderio, 1975). The artefactual nature of the PGA, PGB, 19-hydroxy PG-A and 19-hydroxy PG-B prostaglandins has already been mentioned and it is now generally accepted that all PGs of the A and B series are probably artefacts (Middleditch, 1975). Apart from the 4 major prostaglandins other compounds have been found: PGF-1 $\alpha$, PGF-2 $\alpha$ and PGE-3 (Samuelsson, 1963), 19-hydroxy PGFs and 8-iso 19-hydroxy PGFs (Taylor \& Kelly, 1975) and a range of 8-iso PGs corresponding to all the major prostaglandin components of semen (Taylor, 1979). 

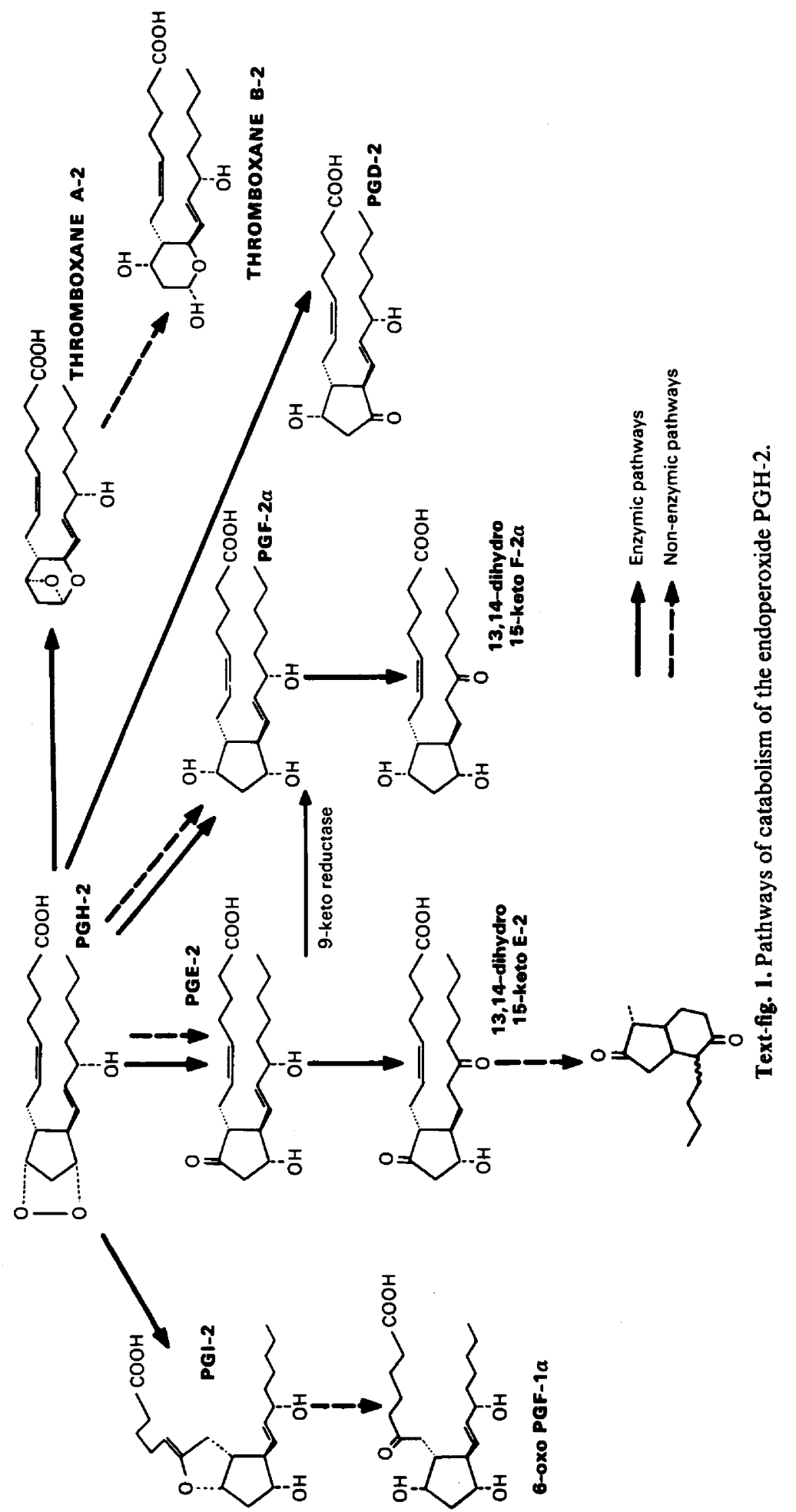
Because of the complexity of human semen it is perhaps unlikely that the minor PG products will play a physiological role. Inspection of a gas chromatogram of an extract of semen (Text-fig. 2) demonstrates the preponderance of the 4 PGs of the $E$ series prostaglandins and a useful approach may be to regard these as the functional PGs and examine the minor components to gain insight into the manner of production of the seminal PGs.

The prostaglandins were so named because early workers had detected smooth muscle stimulating activity in the prostate gland. Today it seems certain that the seminal vesicle is the source of the majority of PGs in semen; this has been shown by the correlation of PG and fructose concentrations in split ejaculates (Eliasson, 1959) and confirmed by the demonstration of PGE production from $\left[{ }^{14} \mathrm{C}\right]$ eicosatrienoic acid incubated with homogenates of human seminal vesicles (Hamberg, 1976). Despite this there is still evidence of prostatic production of PGs (Cavanaugh, Farnsworth, Greizerstein \& Wojtowicz, 1980) and we have shown a high production of PGF-2 $\alpha$ by benign hyperplastic prostatic tissue (F. K. Habib \& R. W. Kelly, unpublished) which suggests that the prostate may well contribute some of the F series PGs to

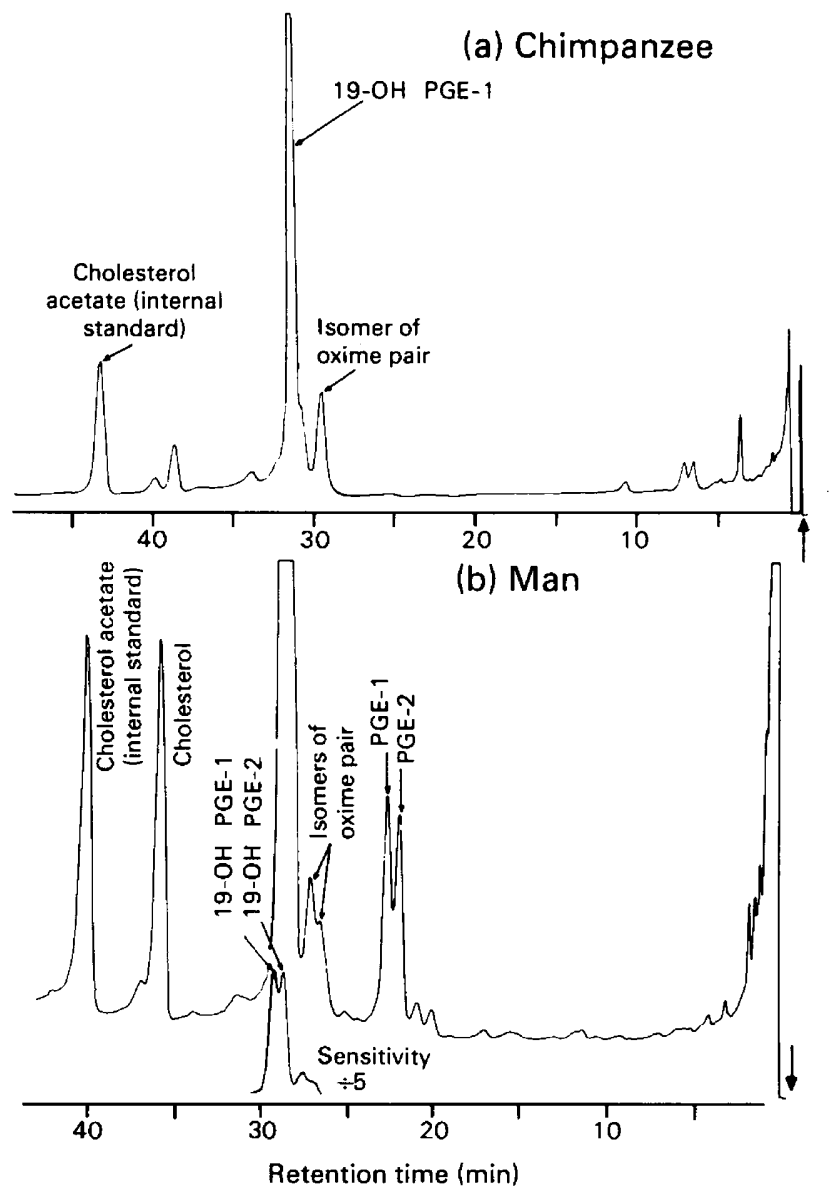

Text-fig. 2. Gas chromatogram of the prostaglandins in (a) chimpanzee and (b) human semen. The prostaglandins are derivatized by in-situ methyl oxime formation, extraction, methylation and trimethylsilyl ether formation. The formation of oxime isomers is an inevitable accompaniment of this process. Chimpanzee semen has a high concentration $(\sim 500 \mu \mathrm{g} / \mathrm{ml})$ of 19-hydroxy PGE-1 with small quantities of 19-hydroxy PGE-2 and virtually no PGE. In contrast, human semen has roughly equal concentrations of 19-hydroxy PGE-1 and 19-hydroxy PGE-2 with substantial amounts of the E prostaglandins. 
semen. One anomaly of PG production seen in the bull is that the seminal vesicles have a high capacity to synthesize PGs (Yamamoto et al., 1977) and yet the semen of this species contains very little PG (Voglmayr, 1973; Kelly et al., 1976).

In general, the species distribution of seminal PGs is difficult to reconcile with their possible functions. Man is the only anima' with substantial quantities of PGE and 19-hydroxy PGE in the semen; the apes and some old world monkeys have high concentrations of 19-hydroxy PGE and very little PGE (Kelly et al., 1976) (Text-fig. 2) and sheep and goats have PGE and PGF (Eliasson, 1959). One species of marsupial, the brush-tailed possum (Trichosurus vulpecula) has 19-hydroxy PGF in the semen (Marley, Selley, Duffield, Roger \& White, 1977) but the concentrations in the semen of eutherian species studied are all $<1 \mu \mathrm{g} / \mathrm{ml}$ and it is possible that the PGs present in smaller amounts are generated by organs other than the seminal vesicles. There are 3 possible roles for the seminal prostaglandins-(1) participation in the ejaculatory process, (2) stimulation of the female reproductive tract after ejaculation, and (3) action on spermatozoa around the time of ejaculation; however, no clear-cut effects can be identified.

Much evidence is available on the action of PGs on the female reproductive tract. Early work showed that crude extracts of seminal prostaglandins have a relaxing action on human myometrium in vitro (Eliasson, 1959); this can be accounted for by a relaxing action of PGE and also of the 19-hydroxy PGEs, which are the most abundant PGs in human semen (Russell, Taylor \& Kelly, 1979). Relaxation of any part of the female reproductive tract after deposition of semen in the vagina is not so easily demonstrated and attempts to investigate this have given equivocal results (Eliasson \& Posse, 1960). Undoubtedly the vagina is a good route for administration of drugs, but since we know of no direct vascular route from vagina to uterus, PGs absorbed from the vagina would have to traverse the lungs, with their high capacity for PG metabolism, and an uncertain quantity of PG would reach the uterus or oviducts. A second question which remains unanswered is how relaxation of the uterus could facilitate transport of spermatozoa. Although evidence for accelerated transport of spermatozoa after PG administration is available (Mandl, 1972; Chang, Hunt \& Polge, 1973; Spilman, Finn \& Norland, 1973), this is for species with very low levels of PGs in the semen (Poyser, 1974).

The second possibility, that seminal PGs can enable or facilitate ejaculation has obvious attractions. PGs have been shown to affect neural transmission and PGs can affect the contraction of the smooth muscle of the male reproductive tract (for a review see Cenedella, 1975); moreover, the co-ordination of ejaculation might demand exceptionally high PG levels. But why are these high levels restricted to primates and sheep? These questions cannot be answered easily and therefore such a role for seminal PGs must remain only a possibility.

The third potential role for seminal PGs is an action on the spermatozoa. This idea has been tested on several occasions and in general no good evidence is available for an action of PGs on spermatozoa. However, several recent findings suggest that further investigations are justified. PGs can affect calcium flux within cells and across membranes; PGE and PGF are believed to act on the sarcoplasmic reticulum to release into the cytoplasm calcium ions which in turn trigger contractions of the muscle fibres (Carsten \& Miller, 1977). Preliminary evidence on the mechanism by which PGF-2 $\alpha$ exerts its luteolytic effect suggests that in the first instance this may be by an increase of $\mathrm{Ca}^{2+}$ influx into the luteal cell (or an intracellular release of bound calcium) which is associated with an inhibition of adenylate cyclase activation (Behrman, 1979). These observations encourage a reappraisal of the possible effects of prostaglandins on calcium flux in the spermatozoa. Such a flux is important since Peterson, Seyler, Bundman \& Freund (1979) have shown that the treatment of human spermatozoa with dibutyryl cyclic AMP and theophylline, a combination designed to raise cAMP levels and of which each component is known to increase sperm motility (for a review see Hoskins \& Casillas, 1975), inhibits the entry of $\mathrm{Ca}^{2+}$ into the spermatozoa by an action which is probably at the plasma membrane.

Neither dibutyryl cAMP nor caffeine are natural components of semen but the prostaglandins are present in huge amounts and the above evidence for their action as 
modulators of intracellular calcium levels, together with evidence that prostaglandins might act directly as ionophores to facilitate the movement of $\mathrm{Ca}^{2+}$ through lipoprotein membranes (Kirtland \& Baum, 1972), suggests that the role of PGs in semen may be to alter $\mathrm{Ca}^{2+}$ flux and thereby control intracellular cAMP levels. If PGs act in this way to regulate sperm metabolism then this should be detectable; one reason why it may not have been is that previous investigations have used $\mathrm{Ca}^{2+}$-free buffer in which to suspend the washed spermatozoa (Eliasson, Murdoch \& White, 1968; Pento, Cenedella \& Inskeep, 1970) and if the primary effect is on $\mathrm{Ca}^{2+}$ transport into the cell, this medium is obviously inappropriate. An effect of 19-hydroxy PGEs in depressing oxidative metabolism in human spermatozoa has been shown (Kelly, 1977) and this explains previous findings of higher respiration rates in washed spermatozoa (Eliasson, 1971). With a $\mathrm{Ca}^{2+}$-containing buffer, an increase in fructose utilization was observed as well as a drop in ${ }^{14} \mathrm{CO}_{2}$ production. However, since respiration is low in human spermatozoa the significance of such an effect may be that it indicates more fundamental metabolic changes.

Any PG action on calcium transport might be expected to result in an association between spermatozoa and PGs. This may be apparent as binding or by an incorporation of PG into the sperm cell. There is some direct evidence for sperm binding of PGs (Bartoszewitcz, Dandekar, Glass \& Gordon, 1975; Mercado, Villalobos, Dominguez \& Rosado, 1978). Moreover, azoospermic men have higher seminal PG levels (Sturde, 1968), and after vasectomy, PG levels in semen tend to rise (Brummer, 1973). The PG concentration in the semen of polyzoospermic men is lower than that in corresponding groups of men with normal sperm counts (Kelly, Cooper \& Templeton, 1979). These findings indicate an inverse relationship between sperm density and PG content of semen which could be interpreted as a removal or binding of PGs by the spermatozoa. Although such spermatozoon-PG interactions may be with the E series PGs, we have been unable to demonstrate any such effect with labelled PGs and therefore interaction might be with the endoperoxides. Because of the non-enzymic routes for PG formation, the PG content of semen could be explained almost entirely by the initial presence of endoperoxides which would break down to give many of the minor PG products found in semen. Moreover, a requirement of different endoperoxide concentrations for different species might result in a qualitative change in the PG content of the semen, since the relatively poor solubility of endoperoxides in semen would be improved by the addition of a 19-hydroxy group. We do in fact observe 19-hydroxy PGEs only in species with very high PG concentrations in the semen. A recent theory of the symmetry of PG receptors (Beddell \& Goodford, 1977) proposes a convenient channel in the receptor opposite the 19 position of the PG skeleton which suggests that a 19-hydroxy group might modify solubility without affecting PGE-like action. If the endoperoxides were the active agents, the apparent removal of PGs by spermatozoa would be explained since there is strong evidence that the endoperoxides and other active intermediates bind covalently to protein (Anderson, Crutchley, Chaudhari, Wilson \& Elring, 1979). The half-life of the endoperoxides in aqueous solution is approximately $5 \mathrm{~min}$ (Hamberg \& Samuelsson, 1974) and this would accord with the relatively short time available for interaction with spermatozoa around the time of ejaculation. We should, therefore, be aware of the possibility that the PGs found in semen are the breakdown products of active species which have fulfilled their function.

\section{Female reproductive tract}

\section{Prostaglandin production by the uterus}

Study of the synthesis of PGs by the uterus is particularly important since an imbalance of PG production is implicated in disorders of menstruation such as dysmenorrhoea (Lundstrom \& Green, 1978) and dysfunctional uterine bleeding (S. K. Smith, M. H. Abel, R. W. Kelly \& D. T. 
Baird, unpublished results). An understanding of the factors which control PG production within the uterus might help to clarify the aetiology of these conditions.

Several studies of the PG levels in human endometrium using a variety of techniques have shown peak levels of PGE-2 of 450-8300 ng/g in the secretory phase of the cycle (Pickles, Hall, Best \& Smith, 1965; Downie, Poyser \& Wunderlich, 1974; Singh, Baccarini \& Zuspan, 1975; Green \& Hagenfeldt, 1975; Levitt, Tobon \& Josimovich, 1975; Maathuis \& Kelly, 1978). The levels of PGE found in endometrium are more variable; they rise during the luteal phase of the cycle but this rise is accompanied by an increase in the ratio of PGF : PGE. The relevance of these levels in tissue samples has been questioned. Green (1979) has suggested a discrepancy between the high tissue levels of PGE and PGF and the amount of PGE and PGF metabolites excreted in the urine. Thus the levels measured may be more of an indication of the biosynthetic capacity of the tissue than its actual production in vivo, since prostaglandins are not stored within tissues. However, an alternative explanation of the discrepancy could be that the endoperoxides generated within the endometrium, which in the tissue sample are converted enzymically and non enzymically to PGE and F, might be transformed in vivo to other PGs by interaction with enzyme systems outside the endometrium.

The current interest in prostacyclin (PGI-2), the short-lived compound which is remarkably active in preventing platelet aggregation (Moncada, Gryglewski, Bunting \& Vane, 1976), and the finding of high levels of its stable metabolite 6-oxo PGF-1 $\alpha$ in homogenates of rat uterus (Fenwick, Jones \& Naylor, 1977), have stimulated examination of prostacyclin occurrence in the human uterus.

Gas chromatography-mass spectrometry measurement of 6-oxo PGF-1 $\alpha$ levels in 38 samples of human endometrium showed that values were undetectable in 24 samples and $<50$ $\mathrm{ng} / \mathrm{g}$ in 31 samples although PGE and PGF levels were $464 \pm 655$ and $644 \pm 954 \mathrm{ng} / \mathrm{g}$ respectively (Kelly, Cooper, Smith \& Abel, 1980). This finding was confirmed in studies using homogenates of human endometrium incubated with $\left[{ }^{14} \mathrm{C}\right]$ arachidonic acid and very low production of 6-oxo PGF-1 $\alpha$ was observed (Abel \& Kelly, 1979). In the same study, myometrial homogenates produced more 6-oxo PGF-1 $\alpha$ than any other PG although the total conversion was low, but when endometrial and myometrial homogenates were incubated together, considerable quantities of 6-oxo PGF-1 $\alpha$ were formed. This demonstrates that the human uterus has a high capacity for prostacyclin synthesis although the actual mechanism by which the endoperoxide intermediates produced by the endometrium might reach and interact with the PGI-2 synthetase present in the myometrium is not clear. PGI-2 production may play a significant role in uterine blood flow since this compound is an inhibitor of platelet aggregation (Moncada et al., 1976), is vasodilatory (Armstrong, Dusting, Moncada \& Vane, 1978) and also has been reported to relax the human uterus in vitro (Omini, Pasargiklian, Foles, Fano \& Berti, 1978).

The non-enzymic paths for the degradation of the endoperoxides (Text-fig. 1) show that the main stable product formed from such decay of PGG-2 and PGH-2 would be PGE-2; it is therefore possible that the PGE-2 seen in endometrium represents non-enzymic breakdown of endoperoxides which in vivo might have interacted with myometrial PGI-2 synthetase. This supposition would mean that the human uterus would produce two compounds with opposite effects, PGF-2 $\alpha$ (a vasoconstrictor and a stimulator of myometrial contractions) and PGI-2 (a vasodilator and inhibitor of myometrial contractions). The ratio of these two prostaglandins would obviously play an important role in determining muscular contractions and blood flow within the uterus and an imbalance would contribute to conditions such as dysfunctional uterine bleeding and dysmenorrhoea.

An important contribution to the treatment of menstrual disorders would be an understanding of the factors which control the proportion of the different PGs within the uterus, in particular what controls the relative rates of PGF-2 and prostacyclin production. It is now well established that oestradiol- $17 \beta$ plays a key role in stimulating prostaglandin production, 
many experiments in vivo with laboratory animals have demonstrated that the optimum conditions for PG production are the action of oestradiol-17 $\beta$ on a progesterone-primed uterus (Ramwell, Leovey \& Sintetos, 1977); studies on human endometrium maintained in organ culture have shown that oestradiol-17 $\beta$ is a powerful stimulant of PGF production (Abel \& Baird, 1980). However, the action of oestradiol-17 $\beta$ in stimulating PG synthesis appears to be by a mechanism different from that of the classical receptor pathway which expresses its uterotrophic action.

The mechanism by which oestradiol-17 $\beta$ exerts uterotrophic action is well understood; it involves the binding of oestradiol- $17 \beta$ to a cytosolic receptor and the complex enters the nucleus to initiate messenger RNA production which in turn induces general protein synthesis (Jensen \& Jacobson, 1962). This mechanism could explain increased PG synthesis by the uterus in response to oestradiol- $17 \beta$ since the PG synthetase could be the protein synthesized, but there are several reasons for suggesting that this does not wholly account for the mechanism of action of oestradiol. Horton \& Poyser (1976) have suggested that there is a discrepancy between the time taken for general protein synthesis to occur (detectable after $4 \mathrm{~h}$ ) and the 60-90 min which elapse before PGF- $2 \alpha$ levels rise in response to an oestradiol-17 $\beta$ infusion into the sheep uterus. Castracane \& Jordan (1976) have shown that co-administration of protein synthesis inhibitors or an anti-oestrogen to rats did not affect the action of oestradiol-17 $\beta$ on PG production by the uterus. Moreover the reported effects of oestradiol- $17 \beta$ on the stimulation of PGF- $2 \alpha$ production

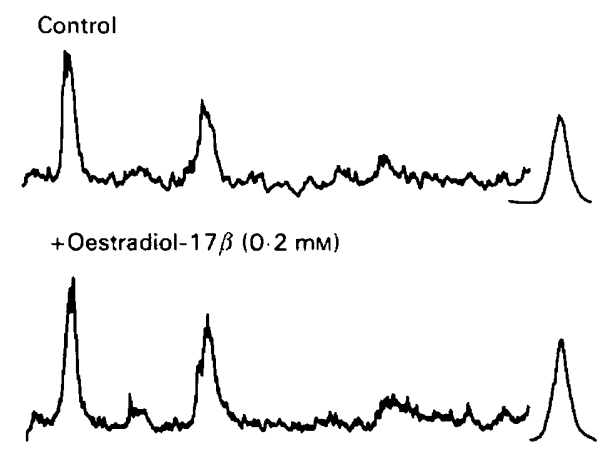

2-OH Oestradiol- $17 \beta(0.2 \mathrm{~mm})$

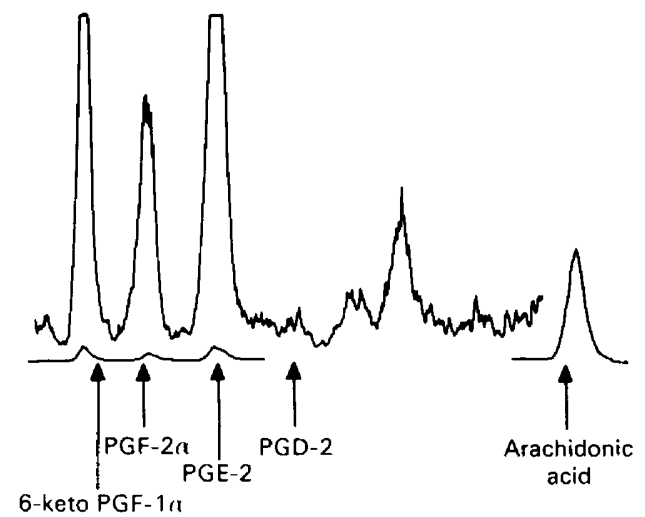

Text-fig. 3. A radio-scan of a thin-layer chromatogram (t.l.c.) of the extracts from an incubation of $0.5 \mu \mathrm{Ci}\left[1-{ }^{14} \mathrm{C}\right.$ larachidonic acid with homogenized secretory endometrium of a woman in the presence of oestradiol-17 $\beta$ and a catechol oestrogen. The t.l.c. sheet (Merck 5735) was developed in the organic phase from a mixture of ethylacetate, iso-octane, acetic acid and water $(110: 50: 20: 100$ by vol.). The large peak nearest the origin (start of trace on left) is of unknown identity. 
by homogenates of guinea-pig uterus were small compared to the action of oestradiol- $17 \beta$ in vivo (Naylor \& Poyser, 1975). We have therefore examined the possibility that catechol metabolites of oestradiol-17 $\beta$ may be active in stimulating PG synthesis within the uterus. A broken-cell preparation of whole rat uterus or human endometrium was used, and it was found that human (Text-fig. 3) and rat uterus can be stimulated greatly by $2,3,17 \beta$-trihydroxy oestra-1,3,5(10)-triene (2-hydroxy oestradiol) which is several times as effective as oestradiol$17 \beta$ itself (Kelly \& Abel, 1980a, b).

Although the stimulation of PG synthesis by 2-hydroxy oestradiol is also seen with adrenalin this effect is not shared with many other cofactors or even catechols. Tryptophan $(200 \mu \mathrm{M})$, glutathione $(200 \mu \mathrm{M})$ and catechol (O-hydroxyphenol; $100 \mu \mathrm{M})$ are inactive and the effect of 2-hydroxy oestradiol-17 $\beta$-acetate, a compound similar in all respects to 2-hydroxy oestradiol except in the derivative at the 17ß-position, is minimal (Kelly \& Abel, 1980a). Moreover, 100 $\mu \mathrm{M}$-2-hydroxy oestriol and 2-methoxy oestrone (a metabolite of 2-hydroxy oestrone) are also inactive, and there is therefore an apparent high specificity for the cofactor requirements of the uterine PG synthetase. Although doses of $100 \mu \mathrm{M}$-adrenalin produce little effect, the rat uterus oxidizes adrenalin rapidly as well as oxidizing catechol oestrogens (R. L. Kennedy, P. L. Taylor, M. H. Abel, \& R. W. Kelly unpublished observations). This is in accordance with the finding that such oxidations often accompany PG synthetase (Takeguchi \& Sih, 1972) and we should therefore interpret apparent inactivity of low levels of adrenalin with caution.

The levels of catechol oestrogens used in these studies may appear high but the catechol oestrogens are liable to oxidation both enzymically (Nelson, Mitchell, Dybing \& Sasame, 1976) and non-enzymically (Gelbke \& Knuppen, 1972), with binding of the oxidized forms to proteins and peptides. This problem can be overcome by the addition of ascorbate to protect the catechols but we have found that ascorbate inhibits the action of catechol oestrogen and therefore cannot be used in experiments of the present type.

We have tested the action of other catechol oestrogens on rat and human uterine tissue; the 4-hydroxylated oestrogens share the stimulatory action of 2-hydroxy oestrogens but do not inhibit 6-oxo PGF-1 $\alpha$ formation. We have therefore demonstrated that catechol oestrogens, which are relatively abundant in human blood (Ball. Evans, Haupt, Hoppen \& Knuppen, 1978), might play a key role both in stimulating PG production and influencing the PGF-2 $\alpha$ to prostacyclin ratio.

\section{Prostaglandin metabolism within the human uterus}

Since, in general, prostaglandins are generated and exert their action in the same tissue or organ, the rate of removal of the active PGs by metabolism is important in controlling their action. There is a marked cyclic variation in the activity in human endometrial cytosol of an NAD-dependent 15-hydroxy prostaglandin dehydrogenase (PGDH; EC 1.1.1.141) (Casey, Hemsell, MacDonald \& Johnston, 1980), which has been shown to act on PGE. This enzyme converts prostaglandins to their relatively inactive 15 -keto metabolites. The activity of this enzyme is maximal between Days 15 and 25 of the menstrual cycle and falls to very low levels on Days 26-28. Since the maximum activity of the PGDH coincides with maximum progesterone production by the corpus luteum, this finding is in accord with earlier observations that PGDH may be regulated by steroid hormones and in particular shows a positive correlation with progesterone concentration (Alam, Russell, Tabor \& Moulton, 1976; Falkay \& Sas, 1978).

Apart from the degradation of PGs to relatively inactive metabolites, they can also be interconverted. The most significant conversion would be by the PG 9-keto reductase enzyme which converts PGE-2 to PGF-2 $\alpha$. Such an enzyme, which is NADPH-dependent, has been found in the ovary (Watson, Sheppherd \& Dodson, 1979) although there are no reports of its occurrence in the human uterus. 


\section{A possible role for $P G s$ in the human uterus}

If it is assumed that it is the synthetic capacity of the tissue which has been measured in previous studies, and with the knowledge that PGDH activity is high in the mid-luteal phase but falls markedly towards the end of the menstrual cycle, then PG concentrations might be significant only around the time of menstruation. The events immediately preceding menstruation are regression of the endometrium followed by a period of stasis and constriction of the spiral arterioles, which characterize the menstruating species (Markee, 1940). These events suggest the production of one or more vasoactive compounds within the uterus. Referring to the vasoactive agent in endometrium which had been transplanted into the eye of rhesus monkeys, Markee (1940) wrote:

'The stimulus which initiates the constriction of the part of the artery outside the area of necrosis is unknown. However the dilation of the iridal vessels immediately outside the transplant at the time of the contraction of the arteries in the basal zone suggests that some agent may be elaborated by the degenerating endometrium and cause changes in the vessels with which it comes into contact."

In the light of today's knowledge it is not unreasonable to assume that this agent is a prostaglandin. Initial vasoconstriction might have several effects. First, it is known that free arachidonic acid is re-incorporated into phospholipids by acyl-coenzyme A ligase and acetyl transferase in an ATP-dependent process (Lands \& Crawford, 1976). These actions result in a free arachidonic acid concentration that is normally low but the ischaemia associated with vasoconstriction would reduce the ATP supply and interrupt the removal of arachidonic acid without effect on its production, thereby increasing the free arachidonic acid concentration. Second, the observed stasis would restrict the removal of any endoperoxide intermediates, thereby increasing the likelihood of their conversion to PGF within the endometrium. Third, the reduced transfer of endoperoxide to the myometrium would restrict the synthesis of the vasodilatory PGI-2 (Text-fig. 4). Thus a positive-feedback situation might exist which would

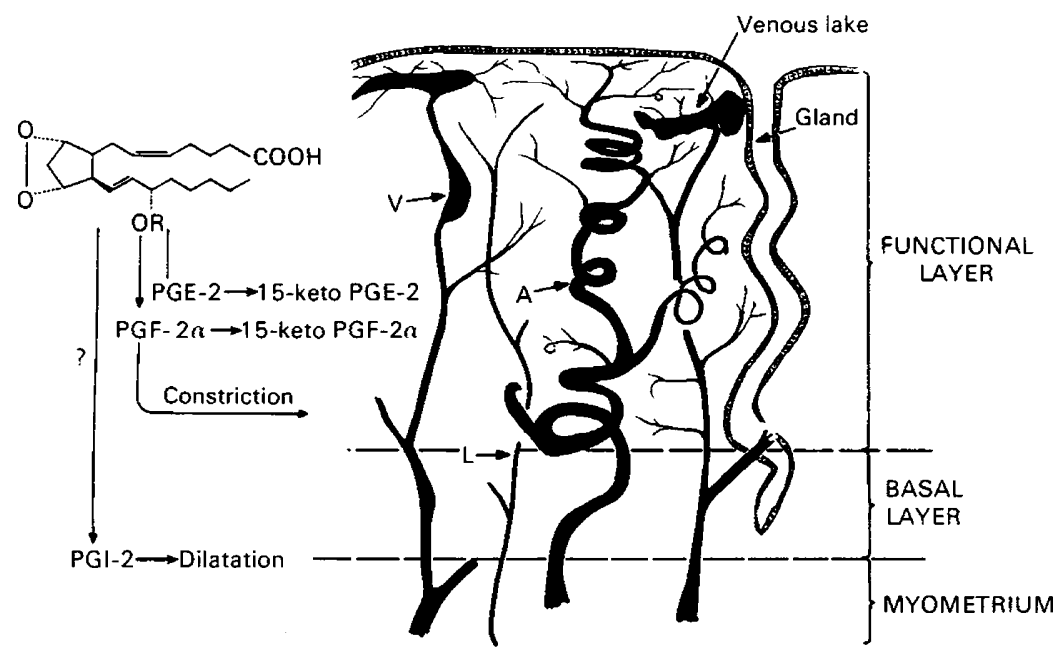

Text-fig. 4. Diagram of the vasculature of the human endometrium showing spiral arterioles (A), veins (V) and lymph drainage (L). Vasospasm which occurs during the early stages of menstruation would restrict any supply of endoperoxide to the myometrium reducing PGI-2 production. At this stage of the cycle, formation of the 15 -keto metabolites is reduced. This combination of factors leads to increased PGF- $2 \alpha$ formation which increases myometrial contractions and vasoconstriction. 
result in increasing PGF-2 $\alpha$ production until the synthesis could no longer be sustained due to severe hypoxia in the endometrium. These events would result in a cyclic release of PGF- $2 \alpha$ which would regulate blood loss and account for the events observed by Markee (1940).

\section{Conclusions}

Despite the early discovery of prostaglandins in the human reproductive tract there are still surprising gaps in our knowledge of their role in semen or the uterus. Undoubtedly the failure to understand the significance of the 200-1000 $\mu \mathrm{g}$ prostaglandin/ml fluid in human semen is a result of our inability to explain all the actions of PGE and PGF at the cellular level. At present the only contribution from the study of prostaglandin actions elsewhere is the suggestion that prostaglandins may act by affecting calcium transport or storage; if this is the case in semen then it is likely that their action is on the spermatozoa. The role of PGs produced in the human endometrium is equally tentative. In contrast to the situation in many non-menstruating species in which PGF- $2 \alpha$ the luteolytic agent, it is not known what part the PGF-2 $\alpha$, PGE-2 and PGI-2 that are produced by the human uterus play in the menstrual cycle or whether any PGs are released from this organ. The role of PGS in menstruation needs much further investigation.

\section{References}

Abel, M.H. \& Baird, D.T. (1980) The effect of estradiol-17 $\beta$ and progesterone on prostaglandin production by human endometrium maintained in organ culture. Endocrinology 106, 1599-1606.

Abel, M.H. \& Kelly, R.W. (1979) Differential production of prostaglandin within the human uterus. Prostaglandins 18, 821-828.

Alam, N.A., Russell, P.T, Tabor, M.W. \& Moulton, B.C. (1976) Progesterone and estrogen control of uterine prostaglandin dehydrogenase activity during deciduomal growth. Endocrinology 98, 859-863.

Anderson, M.W., Crutchley, D.J., Chaudhari, A., Wilson, A.G.E. \& Elring, T.E. (1979) Studies on the covalent binding of an intermediate(s) in prostaglandin biosynthesis to tissue macromolecules. Biochem. Biophys. Acta 573, 40-50.

Armstrong, J.M., Dusting, G.J., Moncada, S. \& Vane, J.R. (1978) Cardiovascular actions of prostacyclin (PGI-2), a metabolite of arachidonic acid which is synthesised by blood vessels. Circ. Res. 43, I112-119.

Ball, P., Evans, G., Haupt, O., Hoppen, H.O. \& Knuppen, R. (1978) Radioimmunoassay of hydroxyoestrone. Steroids 31, 249-258.

Bartoszewitcz, W. Dandekar, P., Glass, R.M. \& Gordon, M. (1975) Localization of prostaglandin on the plasmalemma of rabbit sperm. J. exp. Zool. 191, 151-160.

Beddell, C.R. \& Goodford, P.J. (1977) Symmetry in prostaglandins. Prostaglandins 18, 493-502.

Behrman, H.R. (1979) Prostaglandins in hypothalamopituitary and ovarian function. Ann. Rev. Physiol. 41, 685-700.

Brummer, H.C. (1973) Vasectomy and seminal prostaglandins. Fert. Steril. 24, 131-133.

Carsten, M.E. \& Miller, J.D. (1977) Effects of prostaglandins and oxytocin on calcium release from a uterine microsomal fraction. J. biol. Chem. 252 , 1576-1581.

Casey, M.L., Hemsell, D.L., MacDonald, P.C. \& Johnston, J.M. (1980) NAD-dependent 15-hydroxyprostaglandin dehydrogenase activity in human endometrium. Prostaglandins 19, 115-122.

Castracane, V.D. \& Jordan, V.C. (1976) Considerations into the mechanisms of estrogen stimulated uterine prostaglandin synthesis. Prostaglandins 12, 243261.

Cavanaugh, A.H., Farnsworth, W.E., Greizerstein, H.B. \& Wojtowicz, C. (1980) The influence of testosterone and lactogen on synthesis and metabolism of prostaglandin F-2 $\alpha$ by the human prostate. Life Sci. 26, 29-34.

Cenedella, R.J. (1975) Prostaglandins and male reproductive physiology. In Advances in Sex Hormone Research, Vol. I, pp. 325-358. Eds J. A. Thomas \& P. L. Singhal. University Park Press, Baltimore.

Chang, M.C., Hunt, D.M. \& Polge, C. (1973) Effect of prostaglandins on sperm and egg transport in the rabbit. Adv. Biosci. 9, 805-810.

Downie, J., Poyser, N.L. \& Wunderlich, M. (1974) Levels of prostaglandins in human endometrium during the normal menstrual cycle. J. Physiol., Lond. 236, 465-472.

Eliasson, R. (1959) Studies on prostaglandin occurrence, formation and biological actions. Acta physiol. scand. 46, Suppl. 158, 1-73.

Eliasson, R. (1971) Oxygen consumption of human spermatozoa in seminal plasma and a Ringer solution. J. Reprod. Fert. 27, 383-389.

Eliasson, R. \& Posse, N. (1960) The effect of prostaglandin on the non-pregnant human uterus in vivo. Acta obstet. gynec. scand. 39, 112-126.

Eliasson, R., Murdoch, R.N. \& White, I.G. (1968) The 
metabolism of human spermatozoa in the presence of prostaglandin E-1. Acta physiol. scand. 73, 379-382.

Falkay, G. \& Sas, M. (1978) Correlation between the concentrations of prostaglandin dehydrogenase and progesterone in the early human placenta. J. Endocr. 76, 173-174.

Fenwick, L., Jones, R.L. \& Naylor, B. (1977) Production of prostaglandins by the pseudopregnant rat uterus in vitro, and the effect of tamoxifen with the identification of 6-keto prostaglandin F-1 as a mjaor product. Br. J. Pharmac. 59, 191-199.

Gelbke, H.P. \& Knuppen, R. (1972) A new method for preventing oxidative decomposition of catechol oestrogens during chromatography. J. Chromatog. 71, 465-471.

Green, K. (1979) Determination of prostaglandins in body fluids and tissues. Acta obstet. gynec. scand., Suppl. 87, 15-20.

Green, K. \& Hagenfeldt, K. (1975) Prostaglandins in the human endometrium. Gas chromatographic-mass spectrometric quantitation before and after I.U.D. insertion. Am. J. Obstet. Gynec. 122, 611-614.

Hamberg, M. (1976) Biosynthesis of prostaglandin E by human seminal vesicles. Lipids 11, 249-250.

Hamberg, M. \& Samuelsson, B. (1966) Prostaglandins in human seminal plasma. J. Biol. Chem. 241, 257-263.

Hamberg, M. \& Samueisson, B. (1974) Prostaglandin endoperoxides. Novel transformations of arachidonic acid in human platelets. Proc. natn. Acad. Sci. U.S.A. 71, 3400-3404.

Horton, E.W. \& Poyser, N.L. (1976) Uterine luteolytic hormone: a physiological role for prostaglandin F-2. Physiol. Rev. 56, 595-651.

Hoskins, D.D. \& Casillas, E.R. (1975) Hormones, second messengers and the mammalian spermatozoon. In Advances in Sex Hormone Research, Vol. 1, pp. 283-24. Eds J. A. Thomas \& R. L. Singhal. University Park Press, Baltimore.

Jensen, E.V. \& Jacobson, H.I. (1962) Basic guide to the mechanism of estrogen action. Recent Prog. Horm. Res. 18, 387-408.

Jonsson, H.T., Middleditch, B.S. \& Desiderio, D.M. (1975) Prostaglandin in human seminal fluid: two novel compounds. Science, N.Y. 187, 1093-1094.

Kelly, R.W. (1977) Effect of seminal prostaglandins on the metabolism of human spermatozoa. J. Reprod. Fert. 50, 217-222.

Kelly, R.W. \& Abel, M.H. (1980a) Catechol oestrogens stimulate uterine prostaglandin production. $A d v$. Prostaglandins Thromboxane Res. 8, 1369-1370.

Kelly, R.W. \& Abel, M.H. (1980b) Catechol oestrogens stimulate and direct prostaglandin synthesis. Prostaglandins 20,613-626.

Kelly, R.W., Taylor, P.L., Hearn, J.P., Short, R.V., Martin, D.E. \& Marston, J.H. (1976) 19-Hydroxy prostaglandin E-1 as a major component of the semen of primates. Nature, Lond. 260, 544-545.

Kelly, R.W., Cooper, I. \& Templeton, A.A. (1979) Reduced prostaglandin levels in the semen of men with very high sperm concentrations. J. Reprod. Fert. 56, 195-199.

Kelly, R.W., Cooper, I., Smith, S.K. \& Abel, M.H. (1980) The measurement of the production of 6-oxo prostaglandin F-1 by the uterus. In The Role of
Prostaglandins, Prostacyclin and Thromboxanes Measurement, pp.142-154. Eds J. M. Boeynaems \& A. G. Herman. Martinus Nijhoff, The Hague.

Kirtland, S.J. \& Baum, H. (1972) Prostaglandin E may act as a "calcium ionophore". Nature, New Biol. 236, 47-49.

Lands, W.E.M. \& Crawford, C.G. (1976) Enzymes of membrane phospholipid metabolism in animals. In The Enzymes of Biological Membranes Biosynthesis of Cell Components, Vol. 2. pp. 3-85. Ed. A. Martonosi. Plenum, New York.

Levitt, T.M., Tobon, H. \& Josimovich, J.B. (1975) Prostaglandin content of human endometrium. Fert. Steril. 26, 296-300.

Lundstrom, V. \& Green, K. (1978) Endogenous levels of prostaglandin F-2 $\alpha$ and its main metabolites in plasma and endometrium of normal and dysmenorrhoic women. Am. J. Obstet. Gynec. 130, 640-646.

Maathuis, J.B. \& Kelly, R.W. (1978) Concentrations of prostaglandins F-2 $\alpha$ and E-2 in the endometrium throughout the menstrual cycle, after the administration of clomiphene or an oestrogenprogestogen pill and in early pregnancy. J. Endocr. 77, 361-371.

Mandl, J.P. (1972) The effect of prostaglandin E-1 on rabbit sperm transport in vivo. J. Reprod. Fert. 31, 263-269.

Markee, J.E. (1940) Menstruation in intraocular endometrial transplants in the rhesus monkey. Contr. Embryol. Carnegie Instn. 177, 211-308.

Marley, P.G., Selley, M.L., Duffield, A.M., Roger, J.C. \& White, I.G. (1977) 19-OH prostaglandins $F$ in the semen and prostate gland of marsupials. Theriogenology 8, 207-210.

Mercado, E., Villalobos, M., Dominguez, R. \& Rosado, A. (1978) Differential binding of PGE-1 and PGF-2 $\alpha$ to the human spermatozoa membrane. Life Sci. 22, $429-436$.

Middleditch, B.S. (1975) PGA: fact or artifact? Prostaglandins 9, 409-411.

Moncada, S., Gryglewski, R., Bunting, S. \& Vane, J.R. (1976) An enzyme isolated from arteries transforms prostaglandin endoperoxides to an unstable substance that inhibits platelet aggregation. Nature, Lond. 263, 663-665.

Naylor, B. \& Poyser, N.L. (1975) Effect of oestradiol and progesterone on the in vitro production of prostaglandin F-2 $\alpha$ by the guinea pig uterus. $B r . J$. Pharmac. 55, 229-232.

Nelson, S.D., Mitchell, J.R., Dybing, E. \& Sasame, H.A. (1976) Cytochrome P-450 mediated oxidation of 2-hydroxy estrogens to reactive intermediates. Biochem. Biophys. Res. Commun. 70, 1157-1165.

Omini, C., Pasargiklian, R., Foles, G.C., Fano, M. \& Berti, F. (1978) Pharmacological activity of PGI and its metabolite 6-oxo PGF-1 $\alpha$ on human uterus and fallopian tubes. Prostaglandins 15, 1045-1054.

Pento, J.T., Cenedella, R.J. \& Inskeep, E.K. (1970) Effects of prostaglandins $\mathbf{E}$ and $\mathrm{F}$ upon carbohydrate metabolism of ejaculated and epididymal spermatozoa in vitro. J. Anim. Sci. 30, 409-411.

Peterson, R.N., Seyler, D., Bundman, D. \& Freund, M. (1979) The effect of theophylline and dibutyryl cAMP on the uptake of radioactive calcium and 
phosphate ions by boar and human spermatozoa. $J$. Reprod. Fert. 55, 385-390.

Pickles, V.R. (1957) A plain muscle stimulant in the menstruum. Nature, Lond. 180, 1198-1199.

Pickles, V.R., Hall, W.J., Best, F.A. \& Smith, G.N. (1965) Prostaglandins in endometrium and menstrual fluid from normal and dysmenorrheic subjects. $J$. Obstet. Gynaec. Br. Commonw. 72, 185-192.

Poyser, N.L. (1974) Some aspects of prostaglandins in reproduction. Biochem. Soc. Trans. 2, 1196-1200.

Ramwell, P.W., Leovey, E.M.K. \& Sintetos, A.L. (1977) Regulation of the arachidonic acid cascade. Biol. Reprod. 16, 70-87.

Russell, J.A., Taylor, P.L. \& Kelly, R.W. (1979) Preliminary observations on the effects of 19hydroxy prostaglandin E-1 on the activity of the human myometrium in vitro. J. Reprod. Fert. 56, 33-36.

Samuelsson, B. (1963) Isolation and identification of prostaglandins from human seminal plasma. $J$. biol. Chem. 238, 3229-3234.

Singh, EJ., Baccarini, I.M. \& Zuspan, F.P. (1975) Levels of prostaglandins $\mathrm{F}$ and $\mathrm{E}$ in human endometrium during the menstrual cycle. Am. J. Obstet. Gynec. 121, 1003-1006.

Spilman, C.H., Finn, A.E. \& Norland, J.F. (1973) Effect of prostaglandins on sperm transport and fertilization in the rabbit. Prostaglandins 4, 57-64.

Sturde, H.C. (1968) Experimentelle Untersuchungen zur Frage der Prostaglandine und ihrer Beziehungen zur mannlichen Fertilitat. Arzneimittel-Forsch. 18, 895$900,1158-1163,1298-1310$.

Takeguchi, C. \& Sih, C.J. (1972) A rapid photometric assay for prostaglandin synthetase: application to the study in non-steroidal anti-inflammatory agents. Prostaglandins 2, 169-184.

Taylor, P.L. (1979) The 8-iso prostaglandins, evidence for eight compounds in human semen. Prostaglandins 175, 259-267.

Taylor, P.L. \& Kelly, R.W. (1974) 19-Hydroxylated prostaglandins as the major prostaglandins of human semen. Nature, Lond. 250, 665-667.

Taylor, P.L. \& Kelly, R.W. (1975) The occurrence of 19-hydroxy $F$ prostaglandins in human semen. FEBS Letters 57, 22-25.

Voglmayr, J.K. (1973) Prostaglandin F-2a concentration in genital tract secretions of dairy bulls. Prostaglandins 4, 673-678.

von Euler, U.S. (1936) On the specific vaso-dilating and plain muscle stimulating substances from accessory genital glands in man and certain animals (prostaglandin and vesiglandin). J. Physiol., Lond. 88, 213-234.

Watson, J., Sheppherd, T.S. \& Dodson, K.S. (1979) Prostaglandin E-2-9-ketoreductase in ovarian tissues. J. Reprod. Fert. 57, 489-496.

Yamamoto, S., Ogino, N., Ohki, S., Yoshimoto, T., Bhat, S.G., Oka, J. \& Hayaishi, O. (1977) Enzymological studies on PG biosynthesis. In Biochemical Aspects of Prostaglandins and Thromboxanes, pp. 1-13. Eds N. Kharash \& J. Fried. Academic Press, New York. 